Research paper

\title{
Assessing spatiotemporal eco-environmental vulnerability by Landsat data
}

\author{
Yuei-An Liou ${ }^{\mathrm{a}, \mathrm{b}, *}$, Anh Kim Nguyen ${ }^{\mathrm{c}, \mathrm{d}, * *}$, Ming-Hsu Li ${ }^{\mathrm{c}}$ \\ a Center for Space and Remote Sensing Research, National Central University, No. 300, Jhongda Rd., Jhongli District, Taoyuan City 32001, Taiwan, ROC \\ b Taiwan Group on Earth Observations, Hsinchu, Taiwan, ROC \\ c The Graduate Institute of Hydrological and Oceanic Sciences, National Central University, No. 300, Jhongda Rd., Jhongli District, Taoyuan City 32001, Taiwan, ROC \\ d Institute of Geography, Vietnam Academy of Science and Technology, 18 Hoang Quoc Viet Rd., Cau Giay, Hanoi, Viet Nam
}

\section{A R T I C L E I N F O}

\section{Keywords:}

Vulnerability

Eco-environment changes

AHP

Landsat data

Remote sensing

Thua Thien-Hue Province

\begin{abstract}
A B S T R A C T
An indicator of quantifying eco-environmental vulnerability was established by synthesizing 12 variables, mainly retrieved from satellite data with incorporation of analytical hierarchy process (AHP). Six vulnerability levels of potential, slight, light, medium, heavy, and very heavy were graded to depict changes of vulnerability over temporal and spatial scales. The proposed approach was employed to study spatiotemporal eco-environmental vulnerability with Landsat data acquired in 1989, 2003, and 2014 for the Thua Thien - Hue Province, Vietnam. Over the time periods of 1989-2003 and 2003-2014, both heavy and very heavy vulnerability levels exhibit an increasing trend in both magnitude and spatial size: The former raised from $5.9 \%$ in 1989 , to $7.9 \%$ in 2003 , and $15 \%$ in 2014; and the later increased from $1.2 \%$ in 1989 , to $3.2 \%$ in 2003 , and $7.3 \%$ in 2014 . Both levels mainly appeared on urbanized area, bare land, semi-bare land, agricultural land, and sparse forests. In contrast, there was a significant decline in potential vulnerability level with $36.4 \%$ in $1989,30.9 \%$ in 2003 , and $19.2 \%$ in 2014 , while the remaining vulnerability levels slight, light, and medium fluctuated slightly, increased in 2003 and decreased in 2014. Supporting reasons for such changes include: (1) deforestation, agriculture intensification, construction of three hydro-electric projects during the period 2003-2014; and (2) significant expansion of urbanized area leading to differences in thermal signatures in urban areas as compared with rural areas. The findings demonstrate that eco-environmental vulnerability is primarily exaggerated by anthropogenic activities through land use/land cover (LULC) changes and further enhanced by natural processes including disasters in the Thua Thien - Hue Province of Vietnam. The correlation between land surface temperature (LST) and Normalized Difference Built-up Index (NDBI) is found to be positively correlated with $0.87,0.89$, and 0.84 for 1989, 2003, and 2014, respectively. In contrast, LST-Normalized Difference Vegetation Index (NDVI) is found negatively correlated with respect to the spatiotemporal trend of environmental vulnerability with -0.81 , -0.81 , and -0.76 in 1989,2003 , and 2014 , respectively. In addition, areas having potential, slight, and medium thermal environmental levels are decreased from 1989 to 2003 to 2003-2014. At the regional scale, increased anthropogenic activities through land's modification have intensified the eco-environmental vulnerability in the study area. The currently proposed methodology is feasible for evaluating long-term eco-environmental changes processes by using remote sensing data, and valid for the other regions.
\end{abstract}

\section{Introduction}

Environmental changes and their causes increase the need to tackle their consequences on affecting the structural and functional ecosystem (Polsky et al., 2007; Turner et al., 2003). Natural ecosystem and ecoenvironmental vulnerability are sensitive to changes in land use/land cover (LULC) (Boori and Amaro, 2011; Xie et al., 2013; Hao and Ren, 2009; Adger, 2006; Valipour, 2015, 2016). Decision makers are increasingly pressured with challenges of pursuing social and economic developments without causing detrimental impact on the environment (Hinkel, 2011; Ostendorf, 2011; Lawley et al., 2016). While there might have strong correlations among eco-environmental health, LULC, and thermal signatures (Strand et al., 2010). The thermal signature is the apparent thermal status near surface and can be characterized by land surface temperature (Xiong et al., 2012). Urban area is a complex ecoenvironment involving a variety of anthropogenic activities (Zhang et al., 2006). Due to changes of LULC, including distributions of urban sprawl and vegetation, urban areas often present more significant

\footnotetext{
* Corresponding author at: Center for Space and Remote Sensing Research, National Central University, No. 300, Jhongda Rd., Jhongli District, Taoyuan City, 32001, Taiwan, ROC. *** Corresponding author at: The Graduate Institute of Hydrological and Oceanic Sciences, National Central University, No. 300, Jhongda Rd., Jhongli District, Taoyuan City, 32001, Taiwan, ROC.

E-mail addresses: yueian@csrsr.ncu.edu.tw (Y.-A. Liou), rosella0205@gmail.com (A.K. Nguyen).
} 
thermal signatures than less disturbed rural areas. Therefore, thermal signatures are considered as important eco-environmental characteristics representing evolutions in urban micrometeorology affected by LULC changes (Adger, 2000; Mallick et al., 2013; Miller and Small, 2003). Changes in LULC have been not only recognized as a key determinant factor among a broad range of land surface parameters (e.g., land surface temperature, evapotranspiration, runoff, etc.), but also considered as the most significant in terms of affecting the Earth System functioning (Lambin et al., 2003). The eco-environmental vulnerability is defined and governed by four factors: hydro-meteorology signatures, land resource, social economics (human activities), and topography condition, which can be classified into two categories: internal and external vulnerabilities. Internal vulnerability results from the structure of eco-environment itself and is less impacted by external vulnerability, which is influenced by human activities (Nguyen et al., 2016). In view of environmental vulnerability affected by significant LULC changes, there is a strong demand of using high quality geospatial information to visualizing how environmental vulnerability dynamics varied with to LULC changes. Spatiotemporal eco-environmental vulnerability assessment aims to identify the trend and regions where tend to experience vulnerability, and answer the relevant questions: "what are the reasons for vulnerability and can we use this information to support environmental decision making".

In our previous study (Nguyen et al., 2016), we proposed an assessment framework to evaluate the eco-environmental vulnerability in the Thua Thien - Hue Province, Vietnam, with involvement of 16 variables including those extracted from Landsat 8 OLI, digital maps, and in situ measurements. However, in view of long-term environmental monitoring across the region, it often becomes a barrier by using in situ measurements due to their limited spatiotemporal resolution, insufficient historical data, and infeasibility to capture both natural and manmade attributes within a given place and time. Fortunately, the time series of Landsat satellites have made a significant contribution to various fields of environmental studies, such as long-term environmental monitoring; natural and man-made disaster studies; and support of the evaluation of magnitude, dynamics, and spatiotemporal distribution of land surface parameters and eco-environmental vulnerability over timespans of multiple decades (Tehrany et al., 2013; Wilson et al., 2003).

The current work intends to further apply Landsat data to monitor eco-environmental vulnerability by proposing an improved framework over our previous version (Nguyen et al., 2016). Such improved framework is more suitable for long-term eco-environmental monitoring by advancing the illustration of spatiotemporal variability of ecoenvironmental vulnerability using time series of Landsat data to retrieve variables for detecting surface characteristics affecting regional eco-environment. That is, the improved framework resolves the difficulties in obtaining long-term in situ eco-environmental measurements that are required in the previous framework. In addition, the impacts and trends of LULC on environmental vulnerability for the past 25 years were assessed as an example to demonstrate how these remote sensing data can be used to support planners to obtain objective measurements and comparative context. In addition, this study assesses the impacts of past LULC policies on spatiotemporal eco-environmental vulnerability by: (i) evaluating eco-environmental vulnerability changes based on variables retrieved from Landsat TM, ETM, and OLI \& TIRS (Thematic Mapper, Enhanced Thematic Mapper, and Operational Land Imager \& Thermal Infrared Sensor); and (ii) analysing the relationship between land use changes and thermal anomaly by computing correlation coefficient between land surface temperature (LST) and Normalize Difference Built-up Index (NDBI) over the past 25 years (1989-2003-2014). Deliverable products of this study can be used to assist decision makers to deal with comparative context to answer the planning questions such as how anthropogenic processes affect the environment? Does any region of concern have less harmful impacts on the physical environment as compared with the others? Although the
Thua Thien-Hue Province was selected as our study area, the type of data and proposed framework used in the current study should be available and applicable in many moderate and large size regions.

\section{Materials and methods}

\subsection{Materials}

The present study used several data sets free of charge to examine eco-environmental vulnerability changes. Remote sensing data is the main source with meteorological data of three stations only used to compare with the results extracted from satellite data. The data used in the study are listed below:

(1) Remotely sensed Landsat time series images from Landsat 5 TM images (acquired on 08 May 1989; 03 December 1990), Landsat 7 ETM + images (acquired on 21 April 2003; 06 November 2000), and Landsat 8 OLI \& TIRS images (acquired on 27 April 2014; 04 October 2014). Those images acquired in summer months are used to examine the LST and land cover changes with supporting seasonal vegetation features by using the images acquired in winter months.

(2) ASTER digital elevation model (DEM) with spatial resolution of $30 \mathrm{~m}$, and

(3) Meteorological data of three stations, Hue, A Luoi, and Nam Dong used to investigate the trend of temperature (Fig. 1).

(4) Photos of field survey used to correlate the LULC classification with ground features.

\subsection{Methods}

\subsubsection{Image processing}

Seven major steps were performed for image processing: (i) Atmospheric correction was performed for all bands by using Fast Line-of-Sight Atmospheric Analysis of Spectral Hypercubes (FLAASH) (Waner and Chen, 2001) and following the atmospheric correction, the images were geo-referenced to UTM projection, zone 48 North; (ii) Digital numbers (DNs) of thermal bands were converted to spectral radiance and then brightness temperatures are computed; (iii) Land emissivity is estimated based on NDVI method (Sobrino et al., 2008; Valor and Caselles, 1996) and brightness temperatures are converted to LST (Jimenez-Munoz et al., 2009); (iv) Visible bands of images (Landsat 5 TM image acquired on 08 May 1989; Landsat 7 ETM + image acquired on 21 April 2003; and Landsat 8 OLI \& TIRS image acquired on 27 April 2014) were selected to composite to be a single image and land cover classification is performed with Support Vector Machine (SVM) method (Cortes and Vapnik, 1995). There are nine classes of land cover types including dense forest, medium forest, sparse forest, bare land, agricultural land, planted forest, mixed planted forest (semi-bare land, grassland, shrub, and young planted forest), water, and urbanized area. The accuracy assessment was also done for the classified LULC derived from Landsat images with classification accuracy, Kappa statistics coefficients being 0.84 , 089, and 0.88 for 1989, 2003, and 2014, respectively; (v) Urban thermal field variance index (UTFVI) representing microscale temperature variation between urban and rural areas was calculated based on LST by using Eq. (1) (Liu and Zhang, 2011):

$U T F V I=\frac{T_{s}}{T_{s}-T_{\text {mean }}}$

where UTFVI is the urban thermal field variance index; $\mathrm{T}_{s}$ is the LST of certain pixel in degree Celsius $\left({ }^{\circ} \mathrm{C}\right)$; and $\mathrm{T}_{\text {mean }}$ is the mean LST of the whole study area in degree Celsius. To classify thermal field variance index into different levels, histograms are used to reveal the statistical distribution of calculated thermal field variance values from grid cells; (vi) Calculated Normalized Difference Built-up Index (NDBI), Normalized Difference Vegetation Index (NDVI), Normalized Difference Water 


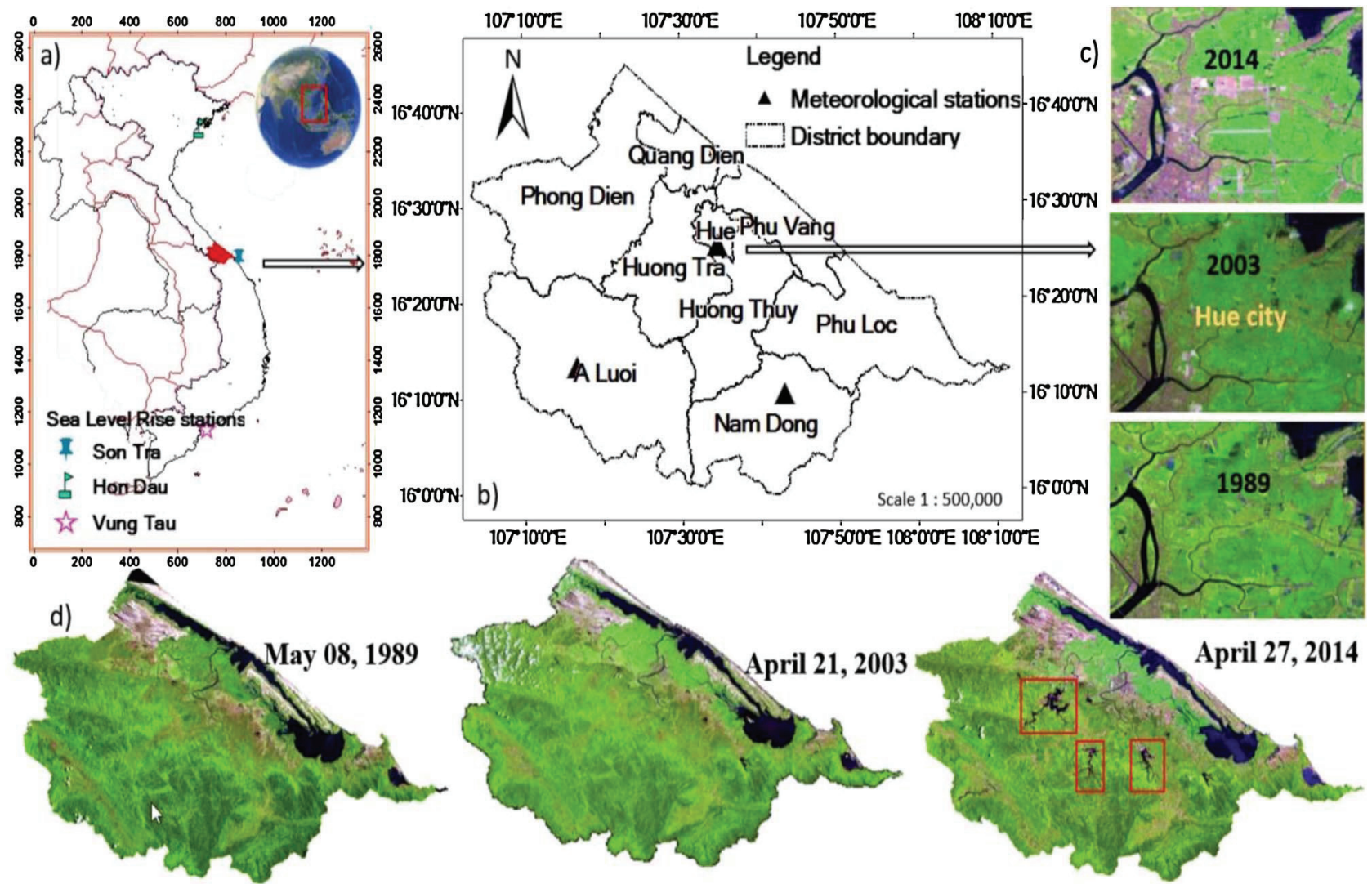

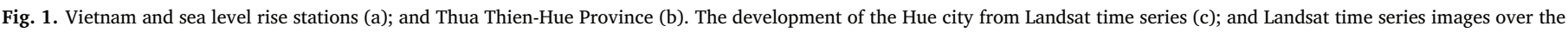

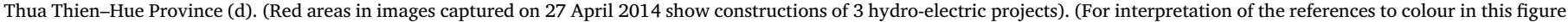
legend, the reader is referred to the web version of this article.)

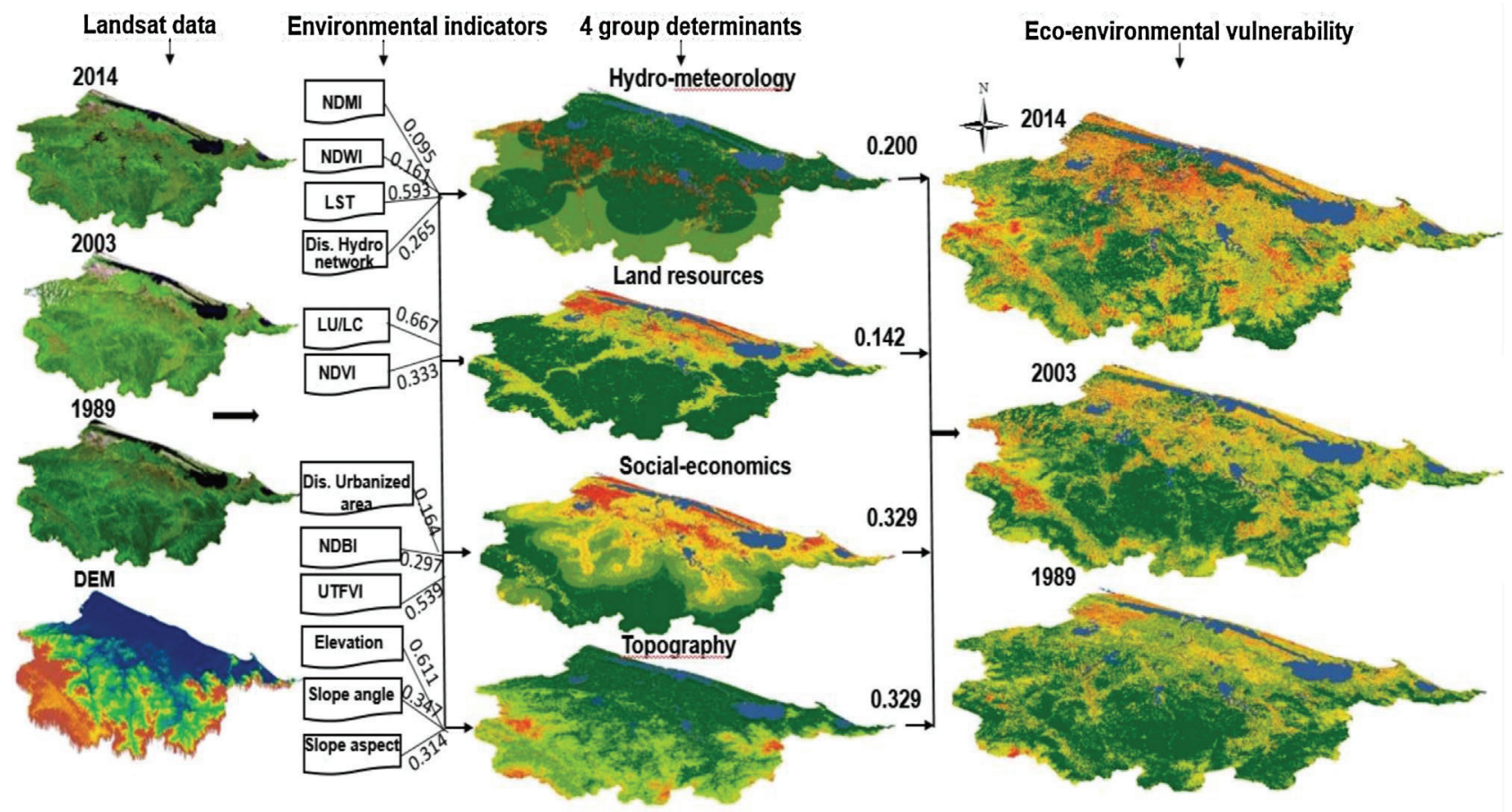

Fig. 2. Long-term eco-environmental vulnerability assessment framework.

Index (IDWI), and Normalized Difference Moisture Index (NDMI) (details of these calculations, refer to Nguyen et al. (2016)); and (vii) Investigated the relationship between LST and NDBI and NDVI.

\subsubsection{Assessment framework}

Two concerned issues of evaluating eco-environmental vulnerability involved in our previous study (Nguyen et al., 2016) were: (i) some indices were generated from in-situ measurement data, especially 
Table 1

Weightings of group variables and variables used for the calculation of eco-environmental vulnerability for the Thua Thien-Hue Province in 1989, 2003, and 2014. Consistency ratio (CR) of four group determinant factors is 0.023 (modified and adapted from Nguyen et al., 2016).

\begin{tabular}{|c|c|c|c|}
\hline $\begin{array}{l}\text { Group variables/Factors } \\
\left(\mathrm{B}_{\mathrm{i}}\right)\end{array}$ & $\begin{array}{l}\text { Global } \\
\text { weight }\left(\mathrm{W}_{\mathrm{i}}\right)\end{array}$ & Variables/Factors $\left(\mathrm{C}_{\mathrm{i}}\right)$ & $\begin{array}{l}\text { Local } \\
\text { weight }\left(w_{i}\right)\end{array}$ \\
\hline \multirow[t]{4}{*}{$B_{1}$. Hydrometeorology } & 0.200 & $\mathrm{C}_{1} \mathrm{NDMI}$ & 0.095 \\
\hline & & $\mathrm{C}_{2}$ NDWI & 0.161 \\
\hline & & $\mathrm{C}_{3} \mathrm{LST}$ & 0.593 \\
\hline & & $\begin{array}{l}\mathrm{C}_{4} \text { Distances from } \\
\text { hydrological network }\end{array}$ & 0.265 \\
\hline \multirow[t]{3}{*}{$B_{2}$. Society-economics } & 0.329 & $\begin{array}{l}\mathrm{C}_{5} \text { Distances from } \\
\text { urbanized area }\end{array}$ & 0.164 \\
\hline & & $\mathrm{C}_{6} \mathrm{NDBI}$ & 0.297 \\
\hline & & $\mathrm{C}_{7}$ UFTVI & 0.539 \\
\hline \multirow[t]{2}{*}{$B_{3}$. Land resources } & 0.142 & $\mathrm{C}_{8}$ LULC & 0.667 \\
\hline & & $\mathrm{C}_{9}$ NDVI & 0.333 \\
\hline \multirow[t]{3}{*}{$B_{4}$. Topography } & 0.329 & $\mathrm{C}_{10}$ DEM & 0.611 \\
\hline & & $\mathrm{C}_{11}$ Slope angle & 0.347 \\
\hline & & $\mathrm{C}_{12}$ Slope aspect & 0.134 \\
\hline
\end{tabular}

meteorological indices such as precipitation, which have certain limited capabilities of reflecting spatial variation of eco-environmental vulnerability due to insufficient spatial resolutions and (ii) thus applicability of previous framework were limited by resolution of station measurement and interpolation technique applied. Therefore, this paper presents a modified framework improved upon the former framework proposed by Nguyen et al. (2016) in order to examine spatiotemporal eco-environmental vulnerability changes over the Thua Thien-Hue Province in 1989, 2003, and 2014. The modified framework aims to effectively use the variables from Landsat data to combat the difficulties associated with historical data missing. Accordingly, spatiotemporal eco-environmental vulnerability maps are generated with consideration of both natural and made attributes then presented this information with unique indices and synthesis maps. Importantly, the improved framework is able to consider the effect of anthropogenic activities as LULC changes on regional eco-environment (Fig. 2). The assessment was evaluated by 12 variables with nine of them constructed from Landsat data and the reminding three variables extracted from DEM. Twelve variables were divided into four group determinant factors consisting of hydrometeorology $\left(B_{1}\right)$, socioeconomics $\left(B_{2}\right)$, land re- sources $\left(B_{3}\right)$, and topography $\left(B_{4}\right) . B_{1}$ includes four variables: $\left(C_{1}\right)$ Normalized Difference Moisture Index (NDMI), $\left(C_{2}\right)$ NDWI, $\left(C_{3}\right)$ LST, and $\left(C_{4}\right)$ Distance from hydrological network extracted from land cover classification. $B_{2}$ includes three variables: $\left(C_{5}\right)$ Distance from urbanized area extracted from land cover classification, $\left(C_{6}\right) \mathrm{NDBI}$, and $\left(C_{7}\right)$ UFTVI. $B_{3}$ includes two variables $\left(\mathrm{C}_{8}\right)$ LULC and $\left(\mathrm{C}_{9}\right)$ NDVI. $B_{4}$ includes 3 variables: $\left(\mathrm{C}_{10}\right)$ DEM, $\left(C_{11}\right)$ slope angle, and $\left(\mathrm{C}_{12}\right)$ slope aspect.

After deriving the 12 variables of interest, eco-environmental vulnerability evaluation was performed for the years 1989, 2003, and 2014 with the aid of an analytical hierarchy process (AHP) and geographical information system (GIS) by using Eqs. (2), (3):

$E V A=\sum_{1}^{4} B_{i} * W_{i}$

$B_{i}=\Sigma_{1}^{n B i} C_{i}{ }^{*} w_{i}$

where EVA denotes the eco-environmental vulnerability, $B_{i}$ is the $i$ th group determinant factor $W_{i}$ is the weight of the $i$ th group determinant factors, $C_{i}$ is the $i$ th variable, $w_{i}$ is the weight of the $i$ th variable, and $n B_{i}$ is the number of variables in group determinant factor $B_{i}$ introduced in Table 1.

To classify vulnerability intensity, the EVA was standardized and compared. In this study, we used histograms to reveal the statistical distribution corresponding to values of grid cells of eco-environmental vulnerabilities raster to classify EVA into six categories, namely potential (1-2.0), slight (2.0-2.6), light (2.6-2.9), medium (2.9-3.0), heavy (3.0-3.5), and very heavy (3.5-4.0).

\section{Results and discussion}

\subsection{Spatiotemporal distribution pattern of eco-environmental vulnerability} levels

Fig. 3 presents eco-environment vulnerability patterns in the Thua Thien-Hue Province during the period of timeframes 1989-2003, and 2003-2014 generated from four determinant factors including hydrometeorology, land resources, topography, and social economics as seen in the Appendices (Figs. A1-A4). An overall perspective of the ecoenvironmental vulnerability exhibited an increasing trend and the vulnerability is heavy in the north, along the coastline and in the center, while it is relatively light in the south. The contribution of

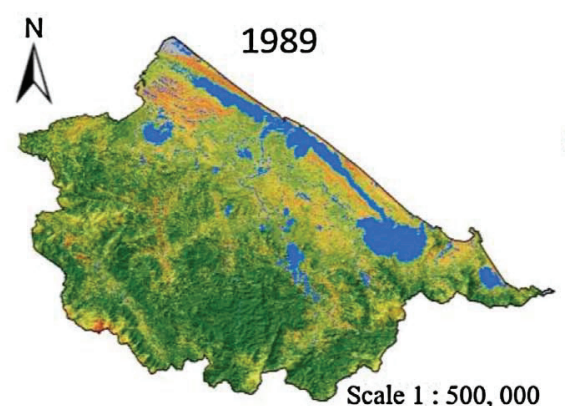

Legend

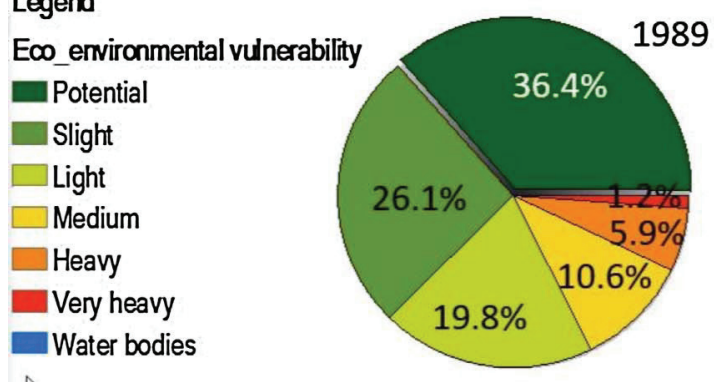

2003
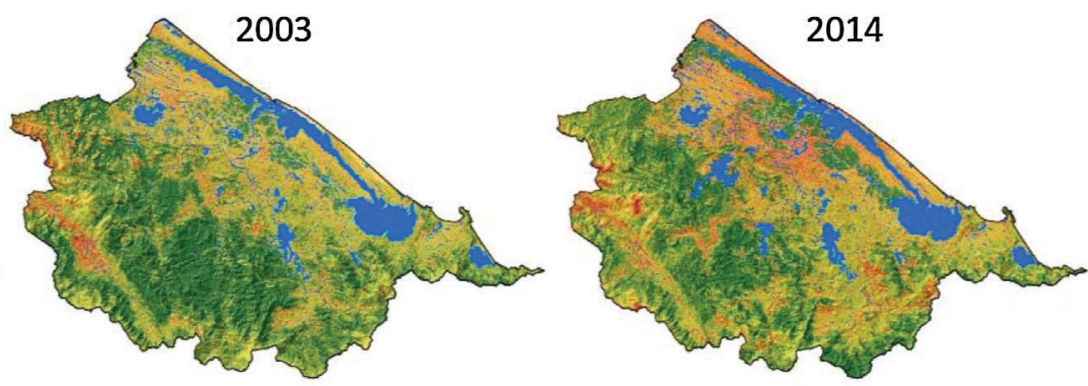

Fig. 3. The map of eco-environmental vulnerability in the Thua Thien-Hue Province in 1989, 2003, and 2014.
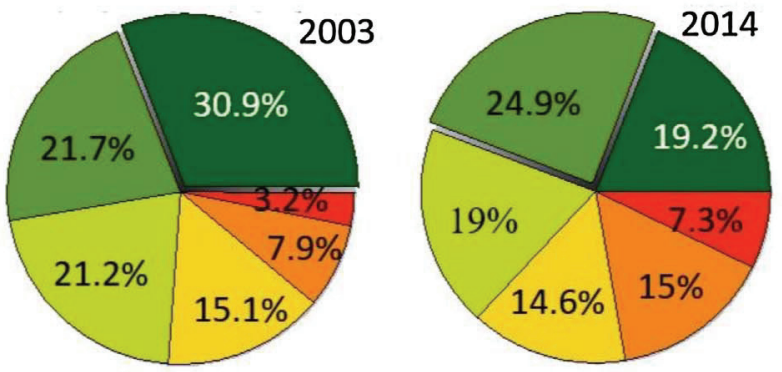
Table 2

Results of statistical analysis and the proportion of each eco-environmental vulnerability level in the Thua Thien - Hue Province in the years 1989,2003 , and 2014.

\begin{tabular}{|c|c|c|c|c|c|c|c|c|c|c|c|c|}
\hline \multirow[b]{2}{*}{ Vulnerability levels } & \multicolumn{4}{|l|}{1989} & \multicolumn{4}{|l|}{2003} & \multicolumn{4}{|l|}{2014} \\
\hline & Grid number & $\%$ & $\begin{array}{l}\text { Mean } \\
\text { EVA }\end{array}$ & SDT & Grid number & $\%$ & Mean EVA & SDT & Grid number & $\%$ & $\begin{array}{l}\text { Mean } \\
\text { EVA }\end{array}$ & SDT \\
\hline Potential & 161363 & 36.4 & 2.28 & 0.57 & 137814 & 30.9 & 2.58 & 0.75 & 85602 & 19.2 & 2.90 & 0.65 \\
\hline Slight & 115584 & 26.1 & & & 96736 & 21.7 & & & 110964 & 24.9 & & \\
\hline Light & 87654 & 19.8 & & & 94261 & 21.2 & & & 84591 & 19.0 & & \\
\hline Medium & 46804 & 10.6 & & & 67220 & 15.1 & & & 64998 & 14.6 & & \\
\hline Heavy & 26368 & 6.0 & & & 35234 & 7.9 & & & 66953 & 15.0 & & \\
\hline Very heavy & 5300 & 1.2 & & & 14076 & 3.2 & & & 32460 & 7.3 & & \\
\hline
\end{tabular}

(a)

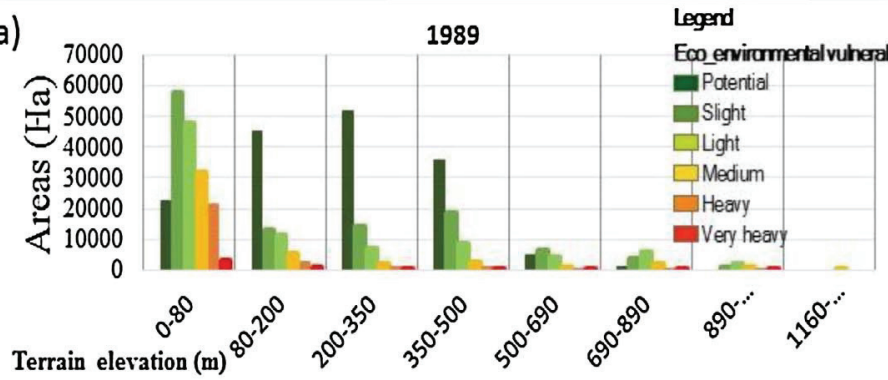

(d)

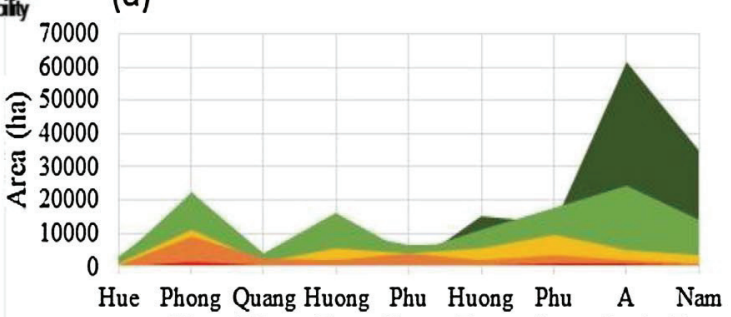

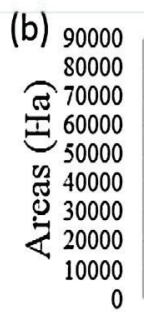

(c)

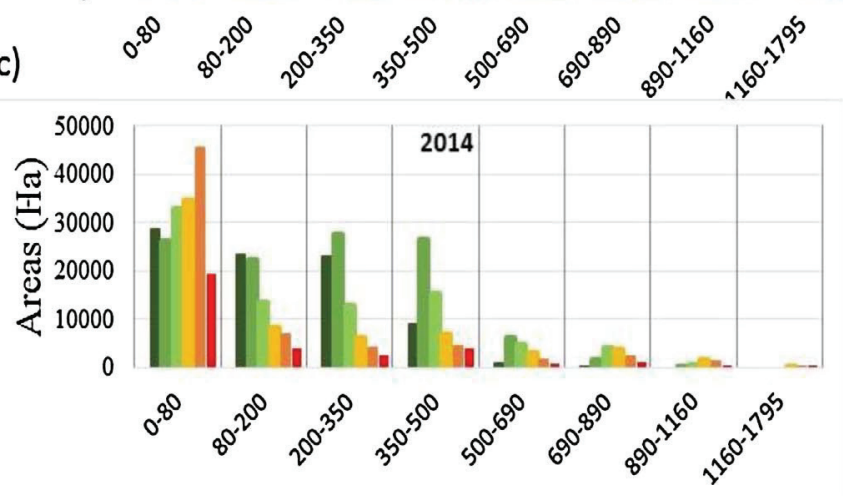

2003

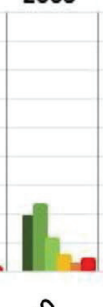

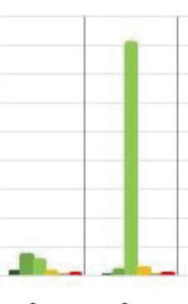

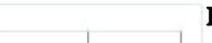

District names in the Thua Thien - Hue Province
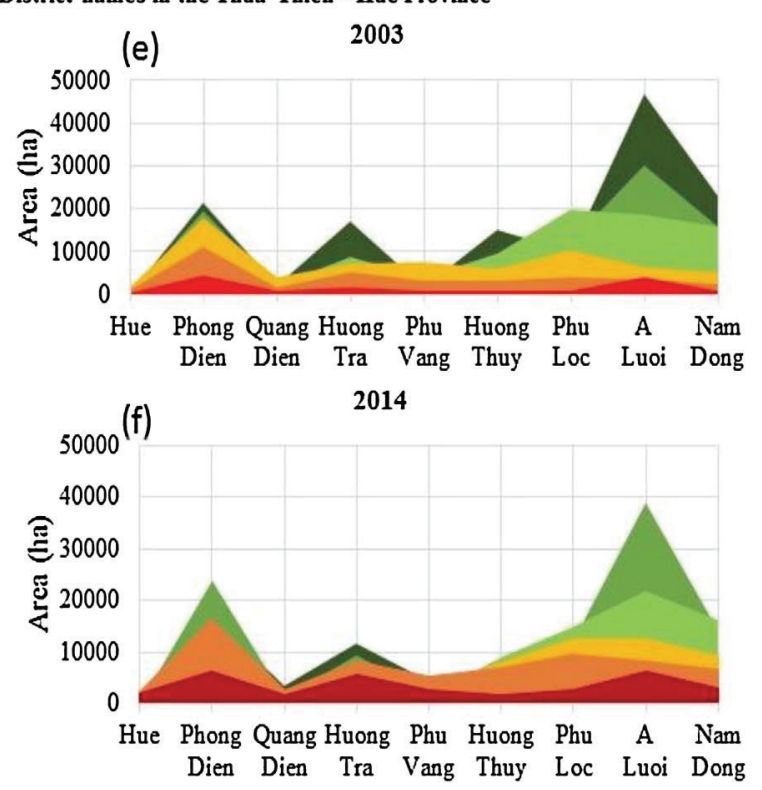

Fig. 4. Spatial distribution of eco-environmental vulnerability in the Thua Thien-Hue Province in 1989, 2003, and 2014 according to elevation and districts.

heavy, and very heavy vulnerability levels shows evolving patterns (from $5.9 \%$ in $1989-7.9 \%$ in 2003 and $15 \%$ in 2014 for heavy vulnerability level; from $1.2 \%$ in 1989 , to $3.2 \%$ in 2003 , and $7.3 \%$ in 2014 for very heavy vulnerability level). In contrast, there was a significant decline in potential vulnerability level (36.4\% in $1989,30.9 \%$ in 2003 , and $19.2 \%$ in 2014). The remaining vulnerability levels include slight, light, medium fluctuating slightly by increasing in 2003 and decreasing in 2014. Table 2 presents the mean values of EVA of the whole study area and statistical computation of each vulnerability level in 1989, 2003, and 2014. In general, eco-environmental vulnerability during 1989-2003-2014 have an upward trend with mean EVA values of 2.28 in 1989, 2.58 in 2003, and 2.89 in 2014. Note that higher EVA values represent more serious eco-environmental vulnerability.

Fig. 4 indicates that eco-environmental vulnerability in medium, heavy, and very heavy levels occurred mainly in Phong Dien, Quang Dien, Nam Dong, and A Luoi districts, showing an evolving trend in their physical size and magnitude. The contributing factors for an upward trend in medium, heavy, and very heavy levels are due to the fact that part of natural forest has been converted to plantation forest, water (due to construction of 3 reservoir hydro-electric dams between 2003 and 2014), and that expansion of urbanized area appears in Quang Dien, Phong Dien, and Nam Dong districts showing sprawl in human settlement. Another supporting reason to explain this trend is that agricultural land in low elevation belt has been invasively converted to urbanized area and agricultural intensification activities continue to explore and practice in higher land so that disturbance of human activities stepping from low to high lands. In addition, higher intensification of medium, heavy, and very heavy levels located in low elevation belt from $0 \mathrm{~m}$ to $80 \mathrm{~m}$ and climbed to higher land from $80 \mathrm{~m}$ to $350 \mathrm{~m}$ in 2014, mainly lying on urbanized area, bare land, semi-bare land, agricultural land, and poor and recovery forests as seen in Fig. 5. 


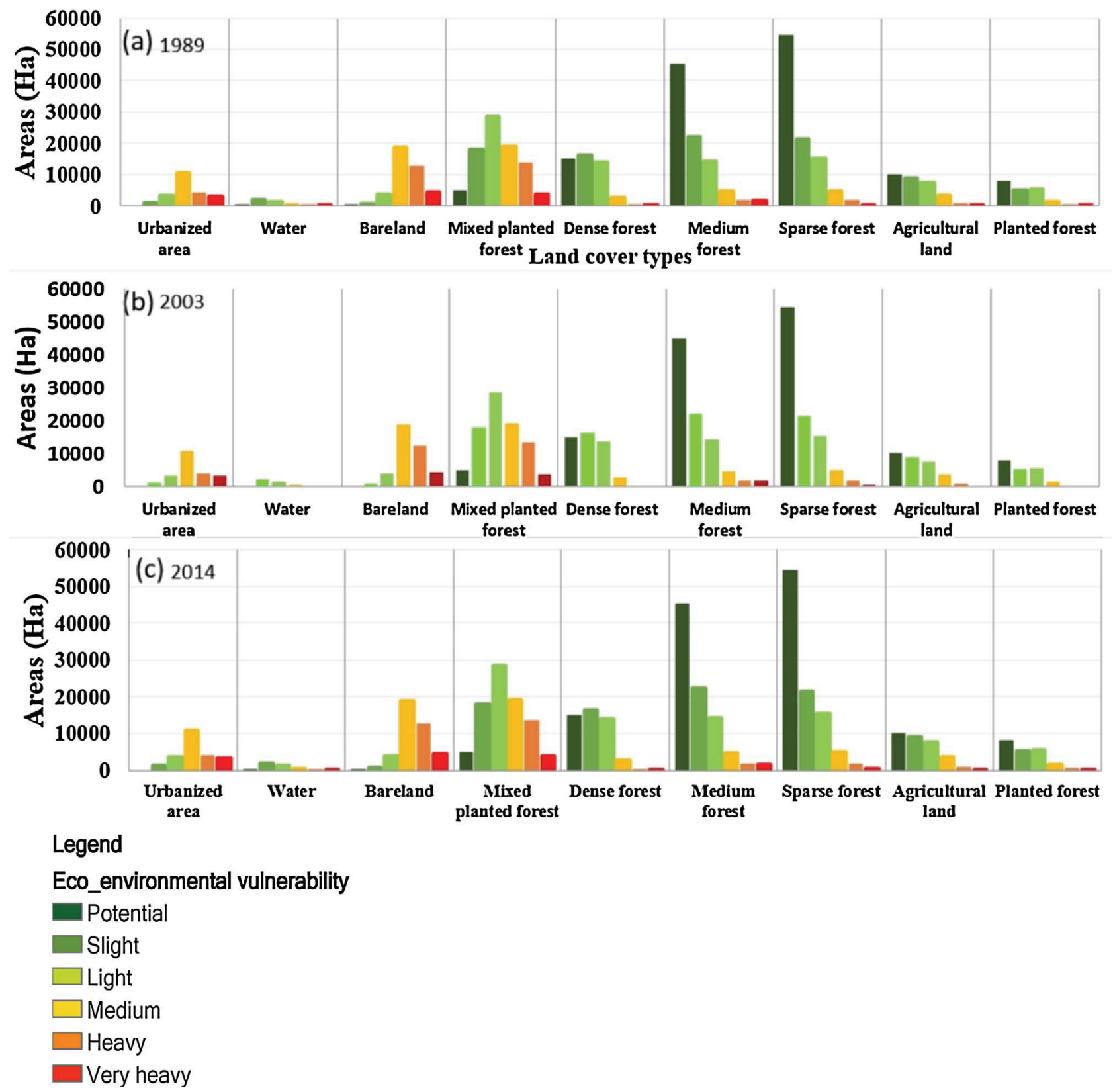

Fig. 5. Spatial distribution of eco-environmental vulnerability in the Thua Thien-Hue Province in 1989, 2003, and 2014 according to land cover types.

\subsection{Discussion of influential factors}

\subsubsection{Land use/land cover changes}

In terms of LULC changes, the driving factors of eco-environmental vulnerability were increased in heavy and very heavy levels and declined in potential levels throughout the periods 1989-2003, and 2003-2014 mainly caused by expansion of urbanized area, cultivation development, and natural forest land narrowing, which can be seen from Figs. $5-7$, in the land cover changes analysis.

Figs. 5-7 show the increase in the physical size of urbanized area with expansion of LST over decades (Fig. 8). There was a dramatic increase in urbanized area and decrease in agricultural land and forest land. Urbanized area had greatest changes during different time periods, from $166.12 \mathrm{~km}^{2}$ in $1989,256 \mathrm{~km}^{2}$ in 2003 , to $530.93 \mathrm{~km}^{2}$ in 2014. There was a significant decrease in agricultural land from $357.25 \mathrm{~km}^{2}$ in 1989 , through $228.94 \mathrm{~km}^{2}$ in 2003 , to $240.88 \mathrm{~km}^{2}$ in 2014. Changes in urbanized area mainly occurred in urban and surrounding areas where cropland was replaced by concrete (buildings, roads, ...etc.) and the reduction of forest land mainly appeared in rural and low mountainous areas where a part of natural forest area was gradually replaced by planted forest and cropland and building. Regarding the reasons for such changes, they can be interpreted as such (i) before 1954, the communities mainly relied on the nature by shifting cultivation and hunting, but in this timeframe the disturbances of humans on the forest were insignificant possible due to low population and long fallow period; (ii) In the period 1967-1973, the forest was destroyed by the wars. The human disturbance becomes a crucial concern since 1975 when the Vietnamese government implemented the New Economic Zone (NEZ) program, which encouraged people to settle in the highland. In this period, the new settlers were lack of proper training and knowledge of sustainable long-term use of abundant land. As a result, the upland forests were heavily abstracted since there was no official regulation to properly govern the forestland management. In addition, humans were free to exploit the forestland for any purposes; (iii) Between 1994 and 2000, the Watershed Management Boards organized the planting of a major part of the hill land. 

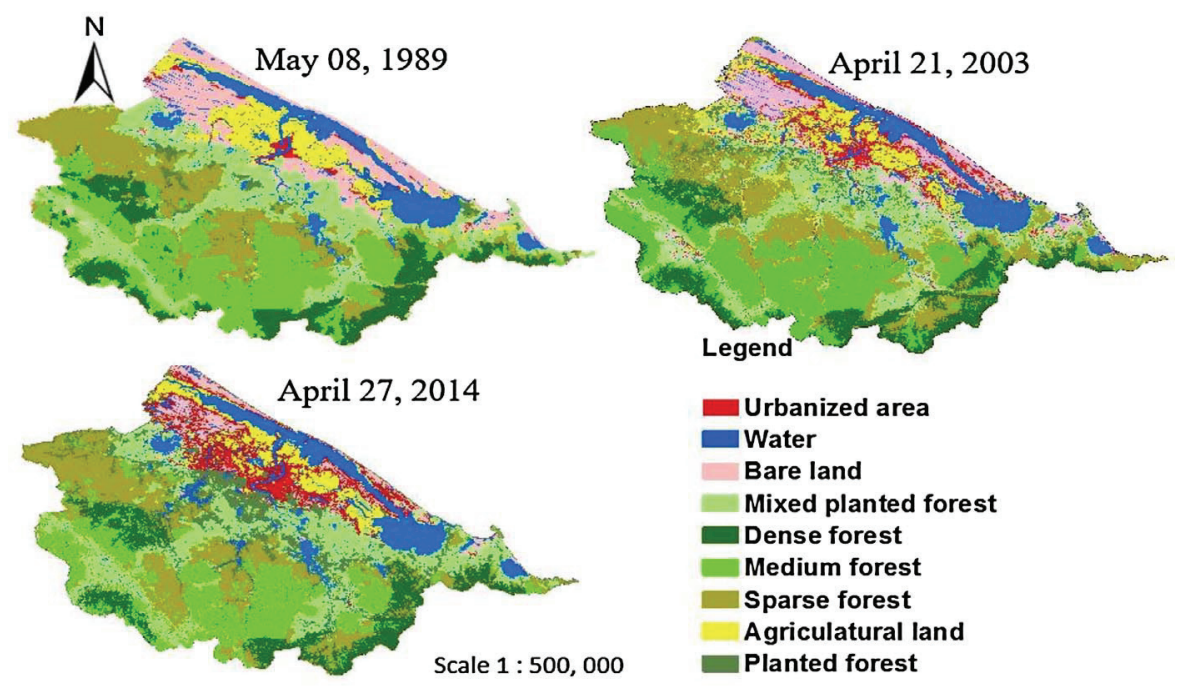

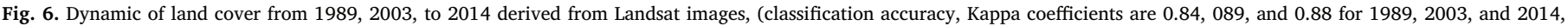
respectively).

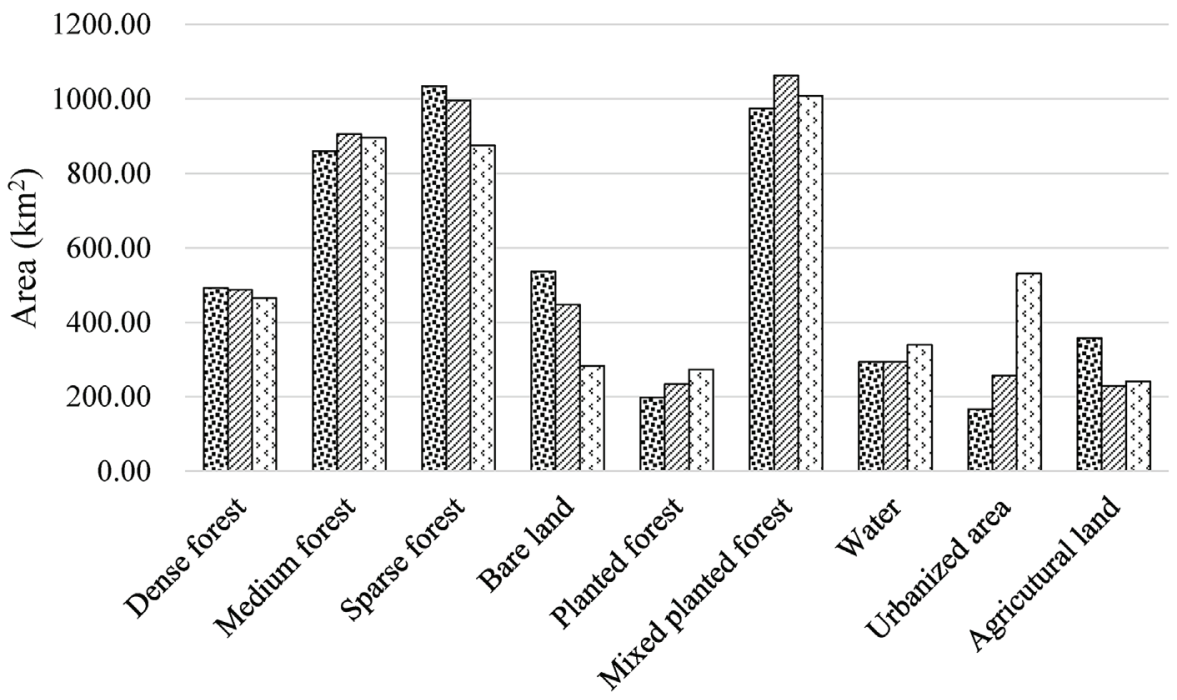

Land cover types

Fig. 7. Land cover changes in past decades 1989-2014 in the Thua Thien-Hue Province.
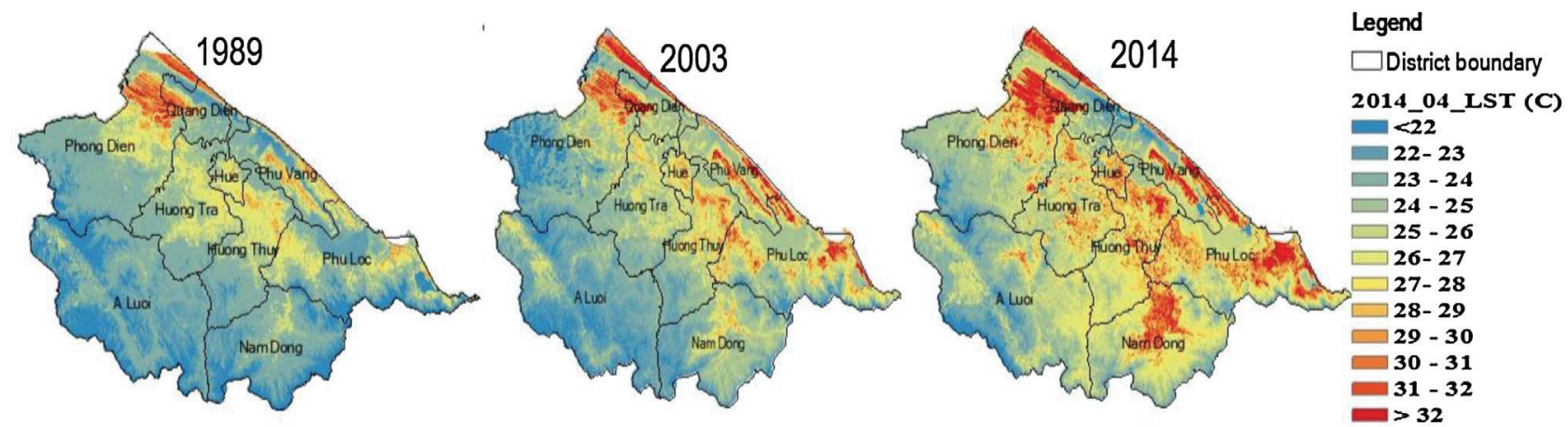

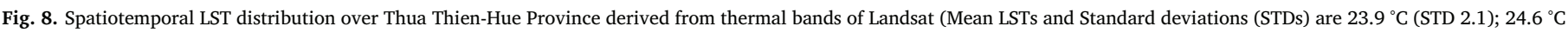
(STD 2.4); and $26.1{ }^{\circ} \mathrm{C}$ (STD 2.7) for 1989, 2003, and 2014, respectively).

Agricultural production has been gradually transferred from the hill slope to the river valleys. Consequently, the planted forests have been vastly redistributed; and (iv) between 2005 and 2008, the Vietnamese government and the Thua Thien-Hue Province strictly enforced the forest protection law, and implemented forest reclassification and zoning, especially in the up-stream protected forest areas (Tran et al., 2010; TTHPPC, 2005). However, it always takes time for the planted forest to grow and the quality of planted forest is incomparable with natural forest, not to mention the fact that the population is high nowadays. Impressively, there was a significant change in water bodies 
Table 3

Changes in LSTs of nine districts over decades.

\begin{tabular}{|c|c|c|c|c|c|c|c|c|}
\hline \multirow[b]{2}{*}{ No } & \multirow[b]{2}{*}{ District names } & \multirow[b]{2}{*}{ Area $\left(\mathrm{km}^{2}\right)$} & \multicolumn{2}{|c|}{08 May 1989} & \multicolumn{2}{|c|}{21 April 2003} & \multicolumn{2}{|c|}{27 April 2014} \\
\hline & & & Mean & Std & Mean & Std & Mean & Std \\
\hline 1 & Hue (urban) & 71.9 & 25.7 & 1.4 & 26.5 & 1.6 & 27.6 & 2.1 \\
\hline 2 & Phu Vang (urban) & 277.2 & 24.9 & 2.2 & 26.5 & 2.7 & 26.7 & 3.5 \\
\hline 3 & Quang Dien (urban) & 162.7 & 25.1 & 2.7 & 26.1 & 3.0 & 26.1 & 3.4 \\
\hline 4 & Phu Loc & 705.8 & 24.1 & 1.8 & 25.8 & 2.5 & 27.7 & 2.8 \\
\hline 5 & Huong Tra & 518.2 & 24.7 & 1.3 & 24.8 & 1.4 & 26.4 & 1.9 \\
\hline 6 & Huong Thuy & 455.9 & 24.6 & 1.7 & 25.3 & 2.0 & 27.3 & 2.0 \\
\hline 7 & A Luoi & 1105.7 & 22.5 & 1.2 & 22.9 & 1.1 & 24.4 & 1.7 \\
\hline 8 & Nam Dong & 643.7 & 22.8 & 1.1 & 24.0 & 1.4 & 26.6 & 2.3 \\
\hline 9 & Phong Dien & 947.1 & 24.8 & 2.6 & 24.3 & 3.1 & 26.4 & 3.2 \\
\hline
\end{tabular}

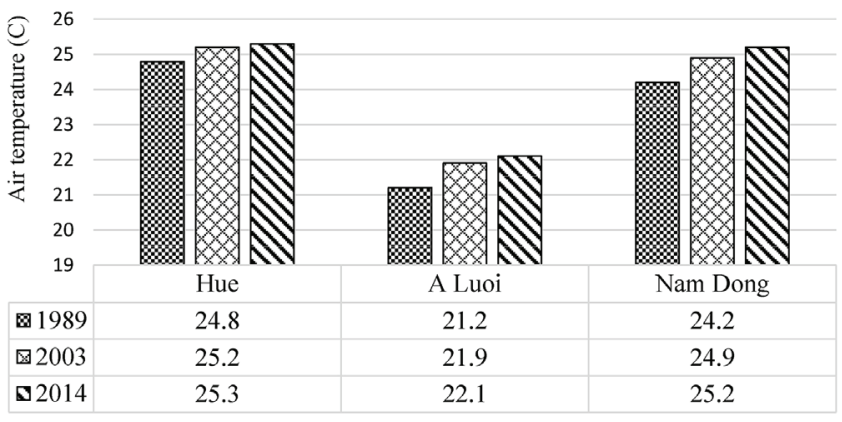

Fig. 9. Annual measured air temperature at 3 stations (Hue, A Luoi, and Nam Dong).

2014
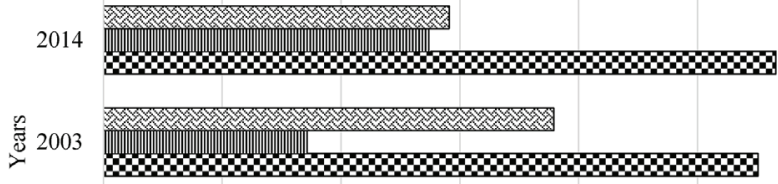

1989

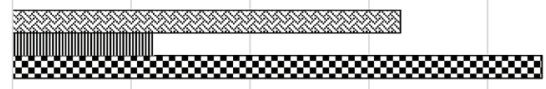
200

$\begin{array}{lrl}400 & 600 \quad 800\end{array}$ 1000 1200

Q Rural population IIII Urban population Total population

Fig. 10. Distribution of population in Thua Thien-Hue Province in 1989, 2003, and 2014.

due to the appearance of 3 reservoir hydro-electric dams constructed after 2010. At the regional scale, the increase of urbanized area, and decrease of cropland and woodland may affect local climate and environmental degradation. Since more people live in the city (Figs. 6, 10), there is an increase in human demands. Fig. 6 shows a significant increase in total population in the Thua Thien-Hue Province throughout the periods from 1989 to 2014. However, the urban population is dramatically increased, while the rural population is significantly declined.

\subsubsection{Land surface temperature (LST)}

The LSTs in urban and rural areas were investigated by estimating mean and standard deviation for each district in the Thua Thien-Hue Province (Table 3). The LSTs in 1989, 2003, and 2014 are shown in Fig. 8. There was an increasing trend in LST in both urban and rural areas (mean LST was increased by $0.7^{\circ} \mathrm{C}$ and $1.5^{\circ} \mathrm{C}$ between the 1989-2003 period and 2003-2014 period, respectively), and the difference in the mean LST between urban and rural areas fluctuated from $0.9{ }^{\circ} \mathrm{C}$ to $2.9^{\circ} \mathrm{C}$. The Fig. 8 shows the evolving patterns of LST from urban to rural areas in 1989, 2003, and 2014, and indicates that each district has a different spatiotemporal pattern of LST. There is an increasing trend for LST from urban to rural areas from 1989 to 2014.
There is no record of precipitation from ground measurement at the time when satellite pass. Therefore, in this study, precipitation is not considered. Annual air temperature from in situ measurement at 3 stations (Hue, A Luoi, and Nam Dong) shows a good agreement with an increasing trend of LST derived from thermal bands of Landsat sensors (Fig. 9). The measured air temperature increased by around $0.5^{\circ} \mathrm{C}$, $1.0{ }^{\circ} \mathrm{C}$, and $0.9{ }^{\circ} \mathrm{C}$ at the Hue, A Luoi, and Nam Dong stations, respectively, throughout the period from 1989 to 2014. The difference in LST from 1989 to 2014 is larger than that in the corresponding measured air temperature. This is possibly due to the larger variation of LST associated with complexity of land cover types as compared to less variability of the air temperature generally measured at height of $2 \mathrm{~m}$. Therefore, difference in LST is higher than those in monthly and annually measured air temperatures.

3.2.3. The correlation analysis between land surface thermal anomalies and land cover change and its association with eco-environmental vulnerability changes

To investigate the relationship between land cover changes and LST variation, several sampling points were randomly taken over the Thua Thien-Hue Province and LST, NDBI, and NDVI values were extracted from the raster data to compute correlation coefficients. The LST-NDBI correlation coefficients (i.e., $0.87,0.89$, and 0.84 for 1989 , 2003, and 2014, respectively) indicate a positive influence of built-up land on urban temperature, implying that the built-up land can intensify the thermal environment in the Thua Thien-Hue Province. In contrast, negative LST-NDVI correlations (i.e., $-0.81,-0.81,-0.76$ in the same period) demonstrate that vegetation can weaken thermal intensity (Fig. 11).

\subsubsection{Remarks for eco-environmental management}

In terms of solutions for short- and long-run visions, we may have a broader view about interaction between natural and human systems to adjust eco-environment in the context of rapid economic development and lessen the negative processes to alert ongoing development plans in a positive way. Understanding the underlying factors that facilitate and inhibit collaboration in eco-environmental settings is an important step towards improvement of public participation in environment (citizen observatories) and resource policy decision making (Selin and Chavez, 1995). Two important issues are always concerned in environmental monitoring and management: (i) defining the problem; and (ii) proposing the solutions. In this study, eco-environmental vulnerability and influential factors are associated with the view of human practice on land's transformation and LULC changes can be attributed to different ways by various applications and contexts (Malczewsk, 2003). Agricultural experts, urban planners, and economic experts would have different perceptions: Agricultural experts tend to develop farming activities from low to high land, from inland to coastal zone; Economic experts take advantages of natural resources for exploration; Urban planners develop and expand from urban to sub-urban and rural areas, and implement construction. Ultimately, it is important to make 

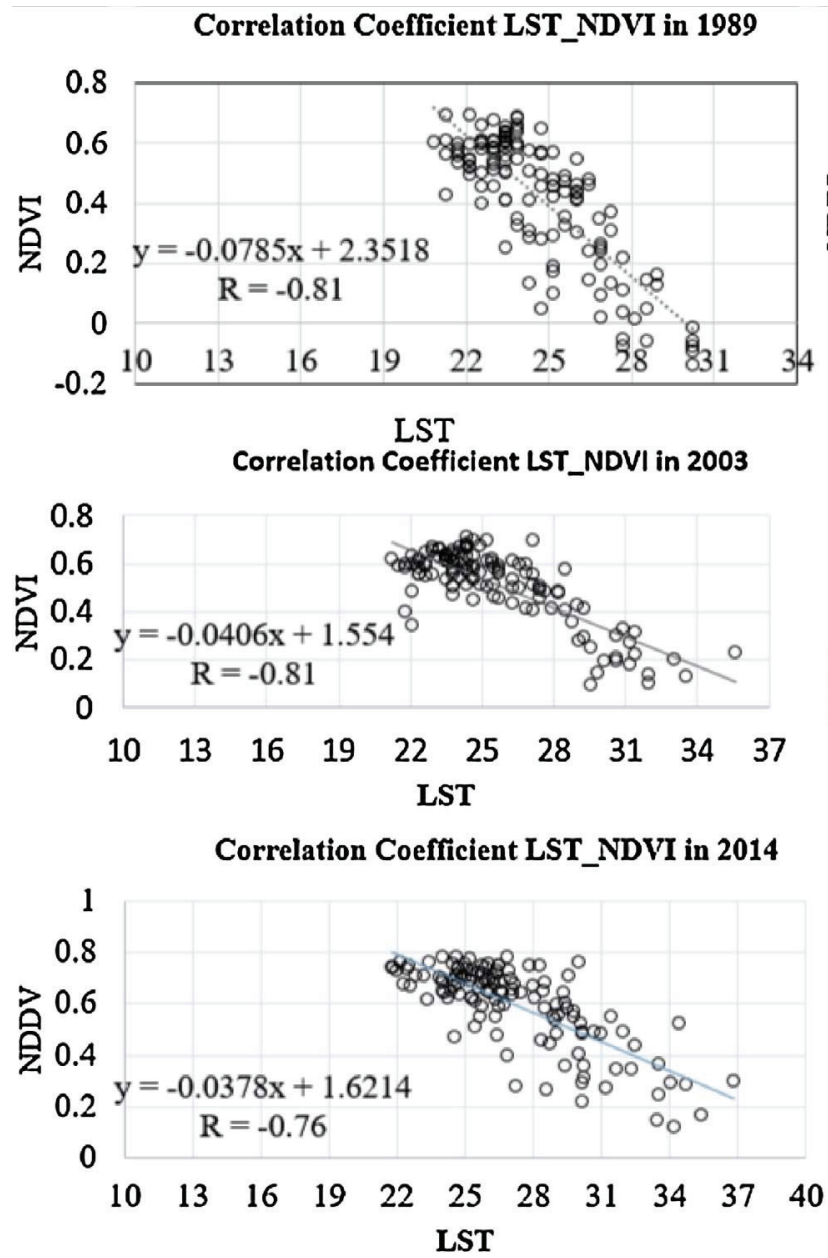

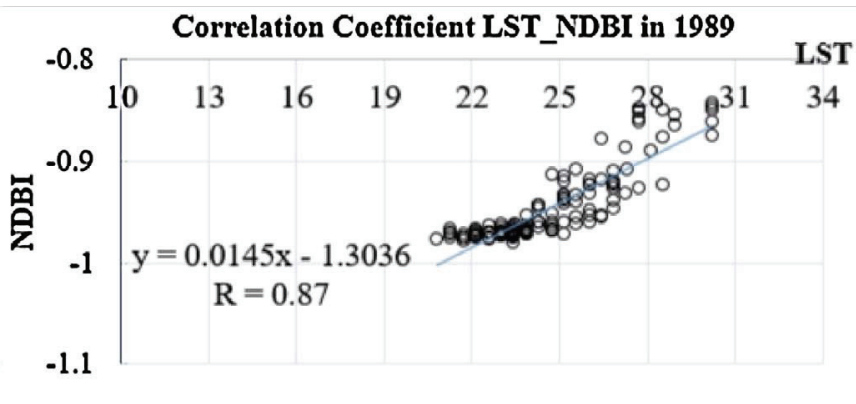

34

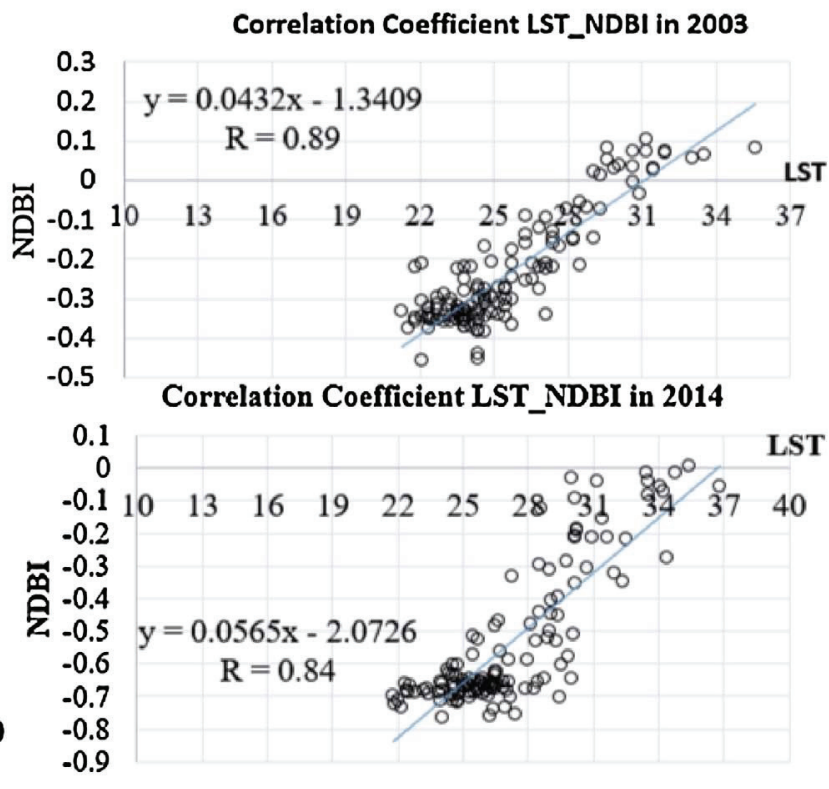

Fig. 11. Correlation coefficients between LST, NDVI, and NDBI in Thua Thien-Hue Province for 1989, 2003, and 2014.

an agreement between development and environmental protection for sustainable ecological development. A persistent and troubling gap between implementation and planning solution requires that the managers must find a new way to enforce proposed solution effectively (Tran et al., 2010). Thus, we suggest that environmentalists, planers, and officials of administrative units simultaneously and closely cooperate to implement what have been proposed in the scientific community. Society and village meeting with representatives of those who involved in the assistance to the planners, and local authorities must resolve the problems be taking into account of people's point of view. Environmental scientists, planers, and local authorities should well inform the people, farmers, and other land users the consequences of the way people use the land. Also, planning should be prepared as early as possible, and land users must be well kept informed of the progress. After all, the more the people willing to involve implementation, the higher the proposed solution can succeed. Although eco-environmental management may be addressed beautifully, its implementation faces a big challenge to achieve a balance between sustainable development and economic boost in the real world.

\section{Conclusions}

This study explored the spatiotemporal eco-environmental vulnerability in the Thua Thien-Hue Province for both time periods of 1989-2003 and 2003-2014 by using variables retrieved from Landsat time series data to investigate evolution of both natural processes and anthropogenic activities. From the results, we draw the following conclusions:
1. In general, time series maps of eco-environmental vulnerability in the Thua Thien-Hue Province in 1989, 2003, and 2014 show an evolving pattern of urban thermal anomalies highly associated with sprawl of urbanized area. Also, they are closely correlated with higher eco-environmental vulnerable levels, namely medium, heavy, and very heavy over the period of interest as the heavy vulnerability level raised from $5.9 \%$ in 1989 , to $7.9 \%$ in 2003 , and $15 \%$ in 2014 ; and the very heavy vulnerability level increased from $1.2 \%$ in 1989 , to $3.2 \%$ in 2003 , and $7.3 \%$ in 2014 .

2. Analysis of eco-environmental vulnerabilities associated with LULC changes in recent 25 years indicates that evolving distributions of heavy and very heavy vulnerability levels mainly occurred on urbanized area, bare land, semi bare land, agricultural land, and sparse forests. In contrast, there is a significant decline in potential vulnerability level (36.4\% in 1989, 30.9\% in 2003, and $19.2 \%$ in 2014). The remaining vulnerability levels slight, light, medium fluctuated slightly by increasing in 2003 and decreasing in 2014 .

3. Supporting reasons for the observed changes are possibly due to: (1) deforestation, agriculture intensification, and construction of three hydro-electric projects during 2003-2014; and (2) significant expansion of urbanized area leading to differences in thermal signatures in urban areas as compared with rural areas. It is readily aware of that intensification and expansion of human activities from lowland to highland have amplified the vulnerability of ecoenvironment in the Thua Thien-Hue Province.

4. The successful assessment framework proposed and practiced in this study can be applied to the other regions by adjusting factors relevant to the concerned variables required. Also, it is necessary to conduct eco-environmental vulnerability assessments for neighbor- 
ing regions of the Thua Thien-Hue Province to further evaluate regional eco-environmental vulnerability in the central Vietnam associated with severe disaster and anthropogenic disturbances.

Additionally, in this study there is not much analysis between ecoenvironmental vulnerability and disaster events, which can become a crucial topic for future investigations. Besides, the study area only focuses on the Thua Thien-Hue Province so that there exists still a big gap for future exploitation to expand the study side and study ecomechanism of eco-environmental vulnerability, not only based on LULC changes, but also considering climate changes and characteristic of disaster events in the region of concern.

\section{Author contributions}

Anh Kim Nguyen came up with research idea through discussion with Yuei-An Liou. She conducted data collection, data processing, and result analysis. The manuscript draft was prepared by Anh Kim Nguyen and enriched by Yuei-An Liou and Ming-Hsu Li. Yuei-An Liou finalized the manuscript.

\section{Conflicts of interest}

The authors declare no conflicts of interest.

\section{Acknowledgments}

This research was financially supported by National Central University, Taiwan through NCU International Student Scholarship, and Ministry of Science and Technology (MOST) of Taiwan under the codes 105-2111-M-008-024-MY2 and 105-2221-E-008-056-MY3. Satellite data are supported by United States Geological Survey (USGS).

\section{Appendix A}

A1. The pair-wise comparison matrix, class weights, and consistency ratio (CR)

Tables A1-A4 present the detail of assigning the weights for the AHP process including hydro-meteorology, social-economics, land resources, and topography.

Table A1

The hydro-meteorology $\left(B_{1}\right)$.

\begin{tabular}{|c|c|c|c|c|c|c|c|}
\hline Factors/Variables & LST & Dis. Hyd. network & NDWI & NDMI & & & \\
\hline LST & 1 & 3 & 4 & 5 & & & \\
\hline Dis. Hyd. network & $1 / 3$ & 1 & 2 & 3 & & & \\
\hline NDWI & $1 / 4$ & $1 / 2$ & 1 & 2 & & & \\
\hline NDMI & $1 / 5$ & $1 / 3$ & $1 / 2$ & 1 & & & \\
\hline Column Sum & 1.783 & 4.833 & 7.500 & 7.500 & & & \\
\hline Normalization & LST & Dis. Hyd. network & NDWI & NDMI & $\begin{array}{l}\text { Weight/ } \\
\text { Row average }\end{array}$ & Row totals & Row totals/average \\
\hline LST & 0.561 & 0.621 & 0.533 & 0.667 & 0.595 & 2.511 & 4.217 \\
\hline Dis. Hyd. network & 0.187 & 0.207 & 0.267 & 0.400 & 0.265 & 1.071 & 4.041 \\
\hline NDWI & 0.140 & 0.103 & 0.133 & 0.267 & 0.161 & 0.633 & 3.933 \\
\hline NDMI & 0.112 & 0.069 & 0.067 & 0.133 & 0.095 & 0.383 & 4.022 \\
\hline Column Sum & 1.000 & 1.000 & 1.000 & 1.000 & 1.000 & & \\
\hline
\end{tabular}

$\lambda_{\max }=4.053$; Consistency index $(\mathrm{CI})=0.020$; Consistency ratio $(\mathrm{CR})=0.016$; Random index $(\mathrm{RI})=0.890$; and $\mathrm{n}=4$; Dis. Hyd. network is distance from hydrological network.

Table A2

The social-economics $\left(B_{2}\right)$

\begin{tabular}{|c|c|c|c|c|c|c|}
\hline Factors/Variables & $\begin{array}{l}\text { Dis. } \\
\text { Dev. } \\
\text { Land }\end{array}$ & $\begin{array}{l}\text { Built- } \\
\text { up } \\
\text { index }\end{array}$ & UFTVI & & & \\
\hline Dis. Dev. Land & 1 & $1 / 2$ & $1 / 3$ & & & \\
\hline Built-up index & 2 & 1 & $1 / 2$ & & & \\
\hline UFTVI & 3 & 2 & 1 & & & \\
\hline Column Sum & 6.000 & 3.500 & 1.833 & & & \\
\hline Normalization & $\begin{array}{l}\text { Dis. } \\
\text { Dev. } \\
\text { Land }\end{array}$ & $\begin{array}{l}\text { Built- } \\
\text { up } \\
\text { index }\end{array}$ & UFTVI & $\begin{array}{l}\text { Weight/ } \\
\text { Row } \\
\text { average }\end{array}$ & $\begin{array}{l}\text { Row } \\
\text { totals }\end{array}$ & $\begin{array}{l}\text { Row } \\
\text { totals/ } \\
\text { average }\end{array}$ \\
\hline Dis. Dev. Land & 0.167 & 0.143 & 0.182 & 0.164 & 0.492 & 3.004 \\
\hline NDBI & 0.333 & 0.286 & 0.273 & 0.297 & 0.894 & 3.008 \\
\hline UFTVI & 0.500 & 0.571 & 0.545 & 0.539 & 1.625 & 3.015 \\
\hline Column Sum & 1.000 & 1.000 & 1.000 & 1.000 & & \\
\hline
\end{tabular}

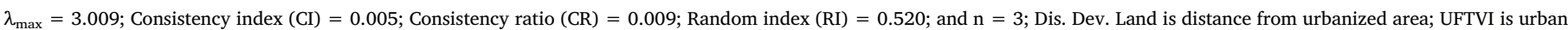
field thermal variance index. 
Table A3

The land resources $\left(B_{3}\right)$.

\begin{tabular}{|c|c|c|c|c|c|}
\hline Factors/Variables & NDVI & LULC & & & \\
\hline NDVI & 1 & $1 / 2$ & & & \\
\hline LULC & 2 & 1 & & & \\
\hline Column Sum & 3.000 & 1.500 & & & \\
\hline Normalization & NDVI & LULC & $\begin{array}{l}\text { Weight/Row } \\
\text { average }\end{array}$ & $\begin{array}{l}\text { Row } \\
\text { totals }\end{array}$ & $\begin{array}{l}\text { Row totals/ } \\
\text { average }\end{array}$ \\
\hline NDVI & 0.333 & 0.333 & 0.333 & 0.667 & 2.000 \\
\hline LULC & 0.667 & 0.667 & 0.667 & 1.333 & 2.000 \\
\hline Column Sum & 1.000 & 1.000 & & & \\
\hline
\end{tabular}

$\lambda_{\max }=2.000 ;$ Consistency index $(\mathrm{CI})=2.000$; Consistency ratio $(\mathrm{CR})=0.000 ;$ Random index $(\mathrm{RI})=0.000 ;$ and $\mathrm{n}=2$.

Table A4

The topography $\left(B_{4}\right)$.

\begin{tabular}{|c|c|c|c|c|c|c|}
\hline Factors/Variables & $\begin{array}{l}\text { Terrain } \\
\text { elevation }\end{array}$ & $\begin{array}{l}\text { Slope } \\
\text { angle }\end{array}$ & $\begin{array}{l}\text { Slope } \\
\text { aspect }\end{array}$ & & & \\
\hline Terrain elevation & 1 & 2 & 4 & & & \\
\hline Slope angle & $1 / 2$ & 1 & 3 & & & \\
\hline Slope aspect & $1 / 4$ & $1 / 3$ & 1 & & & \\
\hline Column Sum & 1.500 & 3.000 & 8.000 & & & \\
\hline Normalization & $\begin{array}{l}\text { Terrain } \\
\text { elevation }\end{array}$ & $\begin{array}{l}\text { Slope } \\
\text { angle }\end{array}$ & $\begin{array}{l}\text { Slope } \\
\text { aspect }\end{array}$ & $\begin{array}{l}\text { Weight/ } \\
\text { Row } \\
\text { average }\end{array}$ & $\begin{array}{l}\text { Row } \\
\text { totals }\end{array}$ & $\begin{array}{l}\text { Row } \\
\text { totals/ } \\
\text { average }\end{array}$ \\
\hline Terrain elevation & 0.667 & 0.667 & 0.500 & 0.611 & 1.843 & 3.015 \\
\hline Slope angle & 0.333 & 0.333 & 0.375 & 0.347 & 1.056 & 3.040 \\
\hline Slope aspect & 0.167 & 0.111 & 0.125 & 0.134 & 0.403 & 3.000 \\
\hline Column Sum & 1.000 & 1.000 & 1.000 & 1.000 & & \\
\hline
\end{tabular}

$\lambda_{\max }=3.018$; Consistency index $(\mathrm{CI})=0.009$; Consistency ratio $(\mathrm{CR})=0.018$; Random index $(\mathrm{RI})=0.520 ;$ and $\mathrm{n}=3$.

\section{A2. Variable/factor description}

\section{A2.1. Hydro-meteorology}

Fig. A1 presents the hydro-meteorology over the Thua Thien-Hue Province in 1989, 2003, and 2014. To evaluate the role of hydro-meteorology

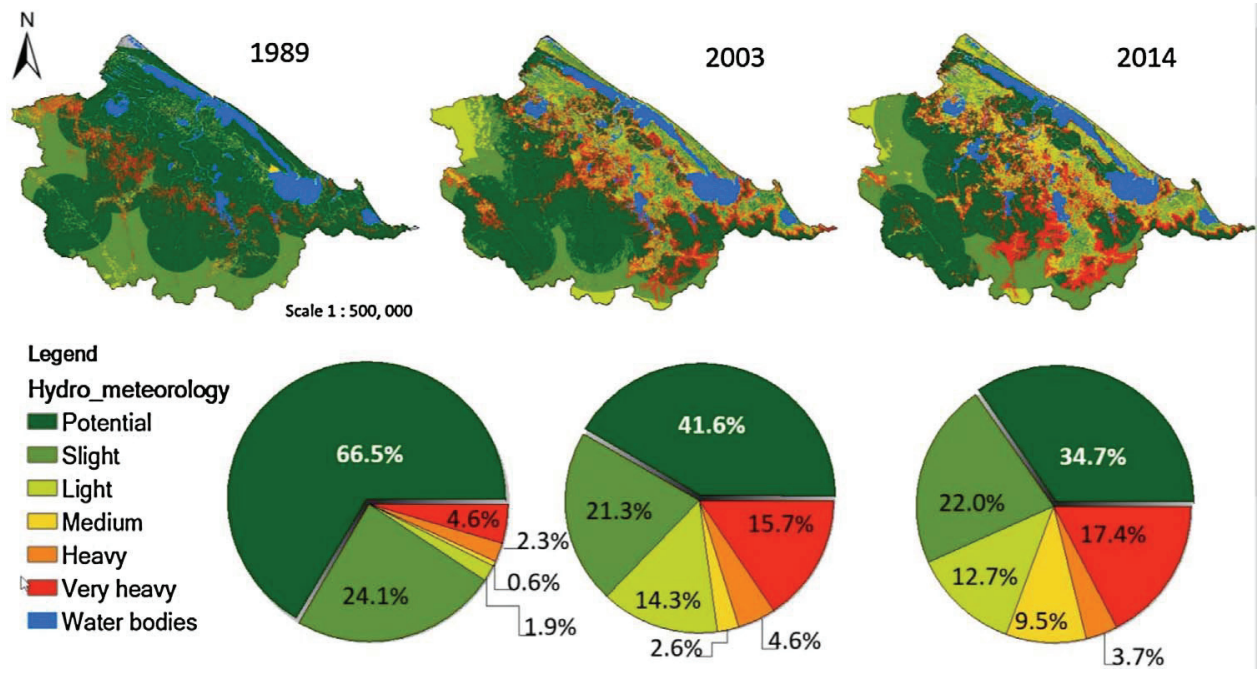

Fig. A1. The map of hydro-meteorological impacts in Thua Thien-Hue Province in 1989, 2003, and 2014.

on the environment, four variables are selected consisting of LST, NDWI, NDMI, and distance from hydrological network retrieved from Landsat data image. Distances are computed by using ArcGIS tools.

These four variables were classified and weighted using AHP as shown in Table A1 and converted into a grid map with $100 \mathrm{~m} \times 100 \mathrm{~m}$ spatial resolution. The Natural Interval Classification method (de Smith et al., 2015) is applied to classify hydro-meteorology map into six levels (potential, slight, light, medium, heavy, and very heavy).

\section{A2.2. Land resource}

Fig. A2 presents land resource impact on the study region in 1989, 2003, and 2014. This map is generated from two variables consisting of NDVI 

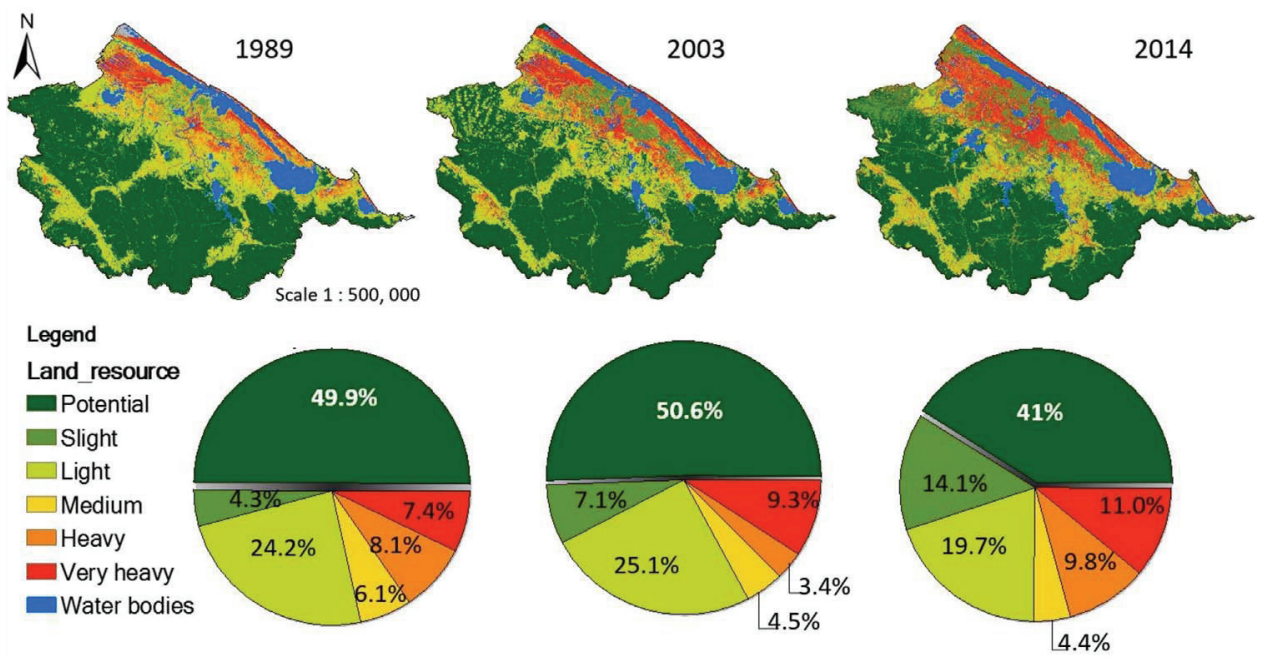

Fig. A2. The map of land resource impacts in Thua Thien-Hue Province in 1989, 2003, and 2014.
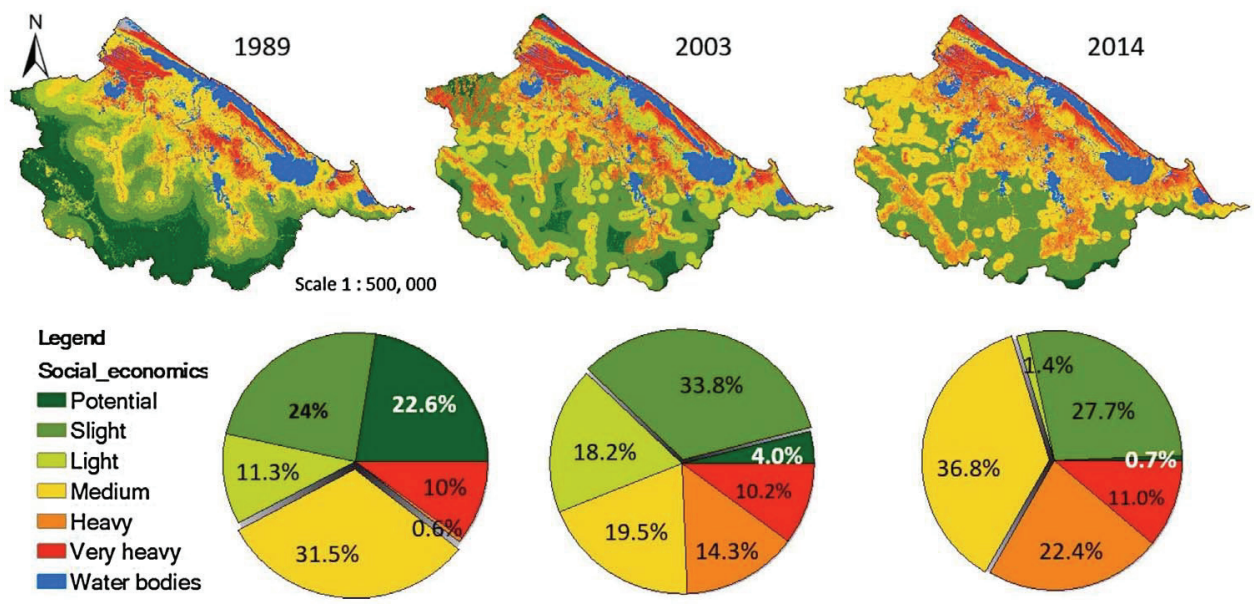

Fig. A3. The map of social-economic impacts in Thua Thien-Hue Province in 1989, 2003, and 2014.

and LULC. AHP method is applied to assign weights for variables as shown in Table A2.

\section{A2.3. Land resource}

Fig. A3 provides socioeconomics impact in 1989, 2003, and 2014. Land resource map is generated from three variables including distance from urbanized area, NDBI, and, UTFVI (Fig. A4).

\section{A2.4. Topography}

Terrain elevation, slope angle, and slope aspect are selected to evaluate topographical impact on environment. Variation of elevation is an important influential factor for regulating evapotranspiration, soil erosion, flood, and landslide, and other processes that could impact environmental vulnerability (Nguyen et al., 2016). Three variables are weighted by using AHP method that is descripted in Table A4. 


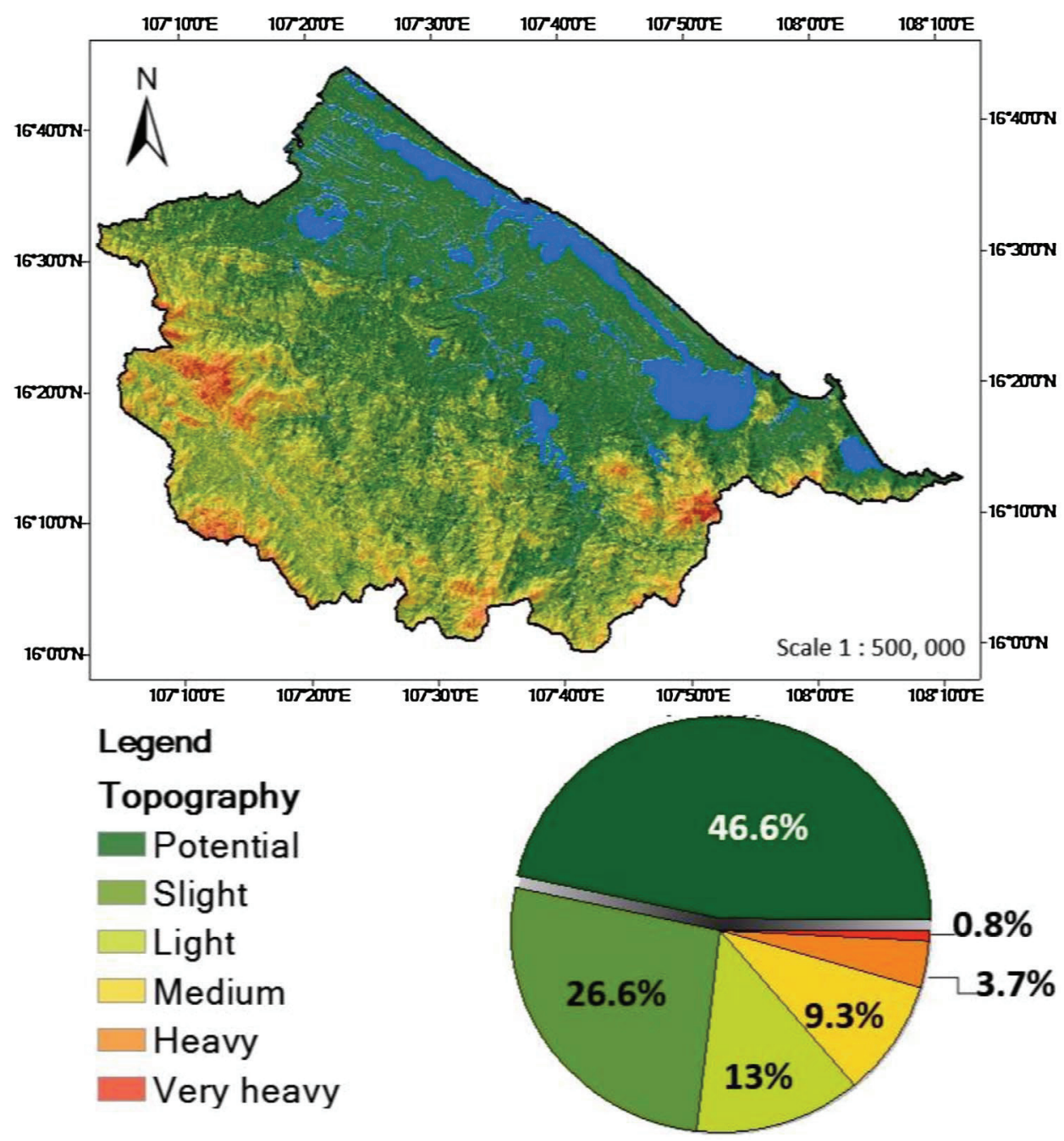

Fig. A4. The map of topographical impacts in Thua Thien-Hue Province in 1989, 2003, and 2014.

\section{References}

Adger, W.N., 2000. Institutional adaption to environmental risk under transition in vietnam. Ann. Assoc. Am. Geographers 90 (4), 738-758.

Adger, N., 2006. Vulnerability. Global Environ. Change 16, 268-281.

Boori, M.S., Amaro, V.E., 2011. Natural and eco-environmental vulnerability assessment through multi-temporal satellite data sets in Apodi valley region, Northeast Brazil. J. Geogr. Reg. Plann. 4 (4), 216-230.

Cortes, C., Vapnik, V., 1995. Support-vector networks. Mach. Learn. 20 (3), 273-297. http://dx.doi.org/10.1023/A:1022627411411.

de Smith, M.J., Goodchild, M.F., Longley, P.A., 2015. Geospatial Analysis, 5th edition. The Winchelsea Press, Winchelsea, UK.

Hao, H.M., Ren, Z.Y., 2009. Land use/land cover change (LULC) and eco-environment response to LULC in Farming-Pastoral zone, China. Agric. Sci. China 8 (1), 91-97.

Hinkel, J., 2011. Indicators of vulnerability and adaptive capacity: towards a clarification of the science-policy interface. Global Environ. Change 21 (1), 198-208.

Jimenez-Munoz, J.C., Cristóbal, J., Sobrino, J.A., Sòria, G., Ninyerola, M., Pons, X., 2009. Revision of the single-channel algorithm for land surface temperature retrieval from landsat thermal-infrared data. IEEE Trans. Geosci. Remote Sens. 47 (1), 339-349.

Lambin, E., Geist, H., Lepers, E., 2003. Dynamics of land-use and land-cover change in tropical regions. Annu. Rev. Environ. Resour. 28, 205-241.

Lawley, E.F., Lewis, M.M., Ostendorf, B., 2016. A remote sensing spatiotemporal framework for interpreting sparse indicators in highly variable arid landscapes. Ecol. Indic. 60, 1284-1297.

Liu, L., Zhang, Y., 2011. Urban heat island analysis using the Landsat TM data and ASTER data: a case study in Hong Kong. Remote Sensing 3 (12), 1535-1552.

Malczewsk, i.J., 2003. GIS-based land-use suitability analysis: a critical overview. Prog. Plann. 62 (1), 3-65 July 2004.

Mallick, J., Rahman, A., Singh, C.K., 2013. Modeling urban heat islands in heterogeneous land surface and its correlation with impervious surface area by using night-time ASTER satellite data in highly urbanizing city, Delhi-India. Adv. Space Res. 52, 639655.
Miller, R.B., Small, C., 2003. Cities from space: potential applications of remote sensing in urban environmental research and policy. Environ. Sci. Policy 6 (2), 129-137.

Nguyen, A.K., Liou, Y.A., Li, M.H., Tran, T.A., 2016. Zoning eco-environmental vulnerability for environmental management and protection. Ecol. Indic. 69, 100-117. http://dx.doi.org/10.1016/j.ecolind.2016.03.026.

Ostendorf, B., 2011. Overview: spatial information and indicators for sustainable management of natural resources. Ecol. Indic. 11, 97-102.

Polsky, C., Neff, R., Yarnal, B., 2007. Building comparable global change vulnerability assessments: the vulnerability scoping diagram. Global Environ. Change 17 (3-4), 472-485.

Selin, S., Chavez, D., 1995. Developing a collaborative model for environmental planning and management. Environ. Manage. 19 (2), 189-195.

Sobrino, J.A., Jiménez-Muñoz, J.C., Sòria, G., Romaguera, M., Guanter, L., Moreno, J. 2008. Land surface emissivity retrieval from different VNIR and TIR sensors. IEEE Trans. Geosci. Remote Sens. 46 (2), 316-327.

Strand, L.B., Tong, S.S., Aird, R., McRae, D., 2010. Vulnerability of eco-environmental health to climate change: the views of government stakeholders and other specialists in Queensland, Australia. BMC Public Health 10, 441.

TTHPPC, 2005. Geography Book (in Vietnamese). Thua Thien - Hue Provincial People Committee, Hue City.

Tehrany, M.S., Pradhan, B., Jebur, M.N., 2013. Remote sensing data reveals ecoenvironmental changes in urban areas of klang valley, Malaysia: contribution from object based analysis. J. Indian Soc. Remote Sens. 41 (4), 981-991.

Tran, P., Marincioni, F., Shaw, R., 2010. Catastrophic flood and forest cover change in the Huong river basin, central Viet Nam: a gap between common perceptions and facts. J. Environ. Manage. 91 (11), 2186-2200.

Turner, B.L., Kasperson, R.E., Matson, P.A., McCarthy, J.J., Corell, R.W., Christensen, L., Eckley, N., Kasperson, J.X., Luers, A., Martello, M.L., Polsky, C., Pulsipher, A., Schiller, A., 2003. A framework for vulnerability analysis in sustainability science. Proc. Natl. Acad. Sci. U. S. A. 100 (14), 8074-8079.

Valipour, M., 2015. Land use policy and agricultural water management of the previous half of century in Africa. Appl. Water Sci. 5 (4), 367-395.

Valipour, M., 2016. Variations of land use and irrigation for next decades under different 
scenarios. Irriga: Braz. J. Irrig. Drain. 1 (1), 262-288.

Valor, E., Caselles, V., 1996. Mapping land surface emissivity from NDVI: application to european, african, and south american areas, 57, 167. Remote Sens. Environ. 184 (18).

Waner, T., Chen, X., 2001. Normalization of Landsat thermal imagery for the effects of solar heating and topography. Int. J. Remote Sens. 22, 773-788.

Wilson, J.S., Clay, M., Martin, E., Stuckey, D., Vedder-Risch, K., 2003. Evaluating environmental influences of zoning in urban ecosystems with remote sensing. Remote Sens. Environ. 86 (3), 303-321.
Xie, H., Wang, P., Huang, H., 2013. Ecological risk assessment of land use change in the poyang lake eco-economic zone, China. Int. J. Environ. Res. Public Health 10 (1), 328-346. http://dx.doi.org/10.3390/ijerph10010328.

Xiong, Y., Huang, S., Chen, F., Ye, H., Wang, C., Zhu, C., 2012. The impacts of rapid urbanization on the thermal environment: a remote sensing study of Guangzhou, South China. Remote Sens. 4, 2033-2056.

Zhang, Y., Yang, Z., Yu, X., 2006. Measurement and evaluation of interactions in complex urban ecosystem. Ecol. Modell. 196, 77-89. 